\title{
Mechanism of Edge Restenosis After Drug-Eluting Stent Implantation
}

\section{- Angulation at the Edge and Mechanical Properties of the Stent -}

Yun Gi Kim, MD; Il-Young Oh, MD; Yoo-Wook Kwon; Jung-Kyu Han, MD;

Han-Mo Yang, MD; Kyung-Woo Park, MD; Hae-Young Lee, MD; Hyun-Jae Kang, MD; Bon-Kwon Koo, MD; Hyo-Soo Kim, MD, PhD

\begin{abstract}
Background: Edge restenosis is not an unusual finding after implantation of drug-eluting stents (DES). We hypothesized that mechanical stress imposed on the stent edge would cause vessel wall injury and inflammation, which may consequently lead to edge restenosis.
\end{abstract}

\begin{abstract}
Methods and Results: In total, 1,496 patients were implanted with a sirolimus-eluting stent (SES), paclitaxel-eluting stent (PES) or zotarolimus-eluting stent (ZES) in Seoul National University Hospital between 2007 and 2009. Binary restenosis occurred in 161 lesions in 119 patients. We retrospectively compared the 3 DES with regard to the percentage of edge stent restenosis among all cases of restenosis. We also evaluated the maximal, minimal, and $\Delta$ (maximal angle-minimal angle) angles. The percentage of edge restenosis was higher for SES than for ZES (37.5\% vs. $16.7 \%, P=0.017)$. Maximal angle at the proximal edge was $64.82^{\circ} \pm 33.46^{\circ}$ for 26 stents with proximal edge restenosis compared with $31.84^{\circ} \pm 31.51^{\circ}$ for 89 stents without proximal edge restenosis $(P=0.001)$. The $\Delta$ angle was also significantly different between the 2 groups $\left(14.81^{\circ} \pm 15.98^{\circ}\right.$ vs. $\left.7.60^{\circ} \pm 8.86^{\circ}, \mathrm{P}=0.035\right)$. Similar findings were observed for distal edge restenosis. Both the maximal angle $\left(39.09^{\circ} \pm 21.04^{\circ}\right.$ vs. $\left.22.71^{\circ} \pm 22.83^{\circ}, \mathrm{P}=0.010\right)$ and $\Delta$ angle $\left(20.23^{\circ} \pm 15.39^{\circ}\right.$ vs. $\left.9.18^{\circ} \pm 9.66^{\circ}, P=0.016\right)$ at the distal edge were significantly different between the 2 groups.
\end{abstract}

Conclusions: Physical stress determined by angulation at the stent edge segment and biomechanical properties of the DES can be considered as one of the plausible mechanisms for edge stent restenosis. (Circ J 2013; 77: 2928-2935)

Key Words: Angulation; Edge restenosis; Hinge motion

I $\mathrm{n}$ the current era of coronary artery stenting, restenosis after stent implantation remains a major limitation of this valuable revascularization procedure, despite procedural advances and technical breakthroughs over the past few decades. ${ }^{1-3}$ The mechanism of restenosis after stent implantation is principally neointimal hyperplasia. ${ }^{4,5}$ Neointimal thickening after mechanical injury or stent implantation predominantly consists of a fibroproliferative reaction initially involving proliferating smooth muscle cells and later dominated by accumulation of extracellular matrix. ${ }^{4,6}$ Neointimal thickening thus plays a decisive role in restenosis after coronary artery stenting, and remains the Achilles' heel of endovascular intervention. Intracoronary brachytherapy (IBT) and drug-eluting stents (DES) were developed to inhibit neointimal proliferation. ${ }^{7,8}$
Although DES still have significant problems, such as late stent thrombosis, ${ }^{6,9-11}$ the encouraging results obtained over the past few years have led to DES playing a major role in interventional cardiology. Conversely, the use of IBT has dramatically declined because of late complications such as edge restenosis or candy wrapper phenomenon, late catch-up phenomenon, or late stent thrombosis. However, edge restenosis, a typical and peculiar side effect of IBT, has been also detected after implantation of sirolimus-eluting stents (SES). ${ }^{12,13}$ DES may have several similarities to IBT not only the antiproliferative effect but also undesired side effects.

Previous animal studies performed by Schwartz et al showed that neointimal proliferation in the porcine coronary artery is a response to injury and follows a proportional relation. ${ }^{14}$

Received October 10, 2012; revised manuscript received July 19, 2013; accepted August 20, 2013; released online October 8, 2013 Time for primary review: 34 days

Cardiovascular Center, Seoul National University Hospital, Seoul (Y.G.K., J.-K.H., H.-M.Y., K.-W.P., H.-Y.L., H.-J.K., B.-K.K., H.-S.K.); Cardiovascular Center, Seoul National University Bundang Hospital, Seongnam (I.-Y.O.); National Research Laboratory for Stem Cell Niche, Seoul (Y.-W.K.); and Innovative Research Institute for Cell Therapy, Seoul National University Hospital, Seoul (Y.-W.K.), Korea

The first 2 authors contributed equally to this work (Y.G.K., I.-Y.O.).

Mailing address: Professor Hyo-Soo Kim, MD, PhD, FAHA, Department of Internal Medicine, Seoul National University Hospital, 101 Daehak-ro, Jongro-gu, Seoul 110-744, Korea. E mail: hyosoo@snu.ac.kr

ISSN-1346-9843 doi:10.1253/circj.CJ-12-1259

All rights are reserved to the Japanese Circulation Society. For permissions, please e-mail: cj@j-circ.or.jp 


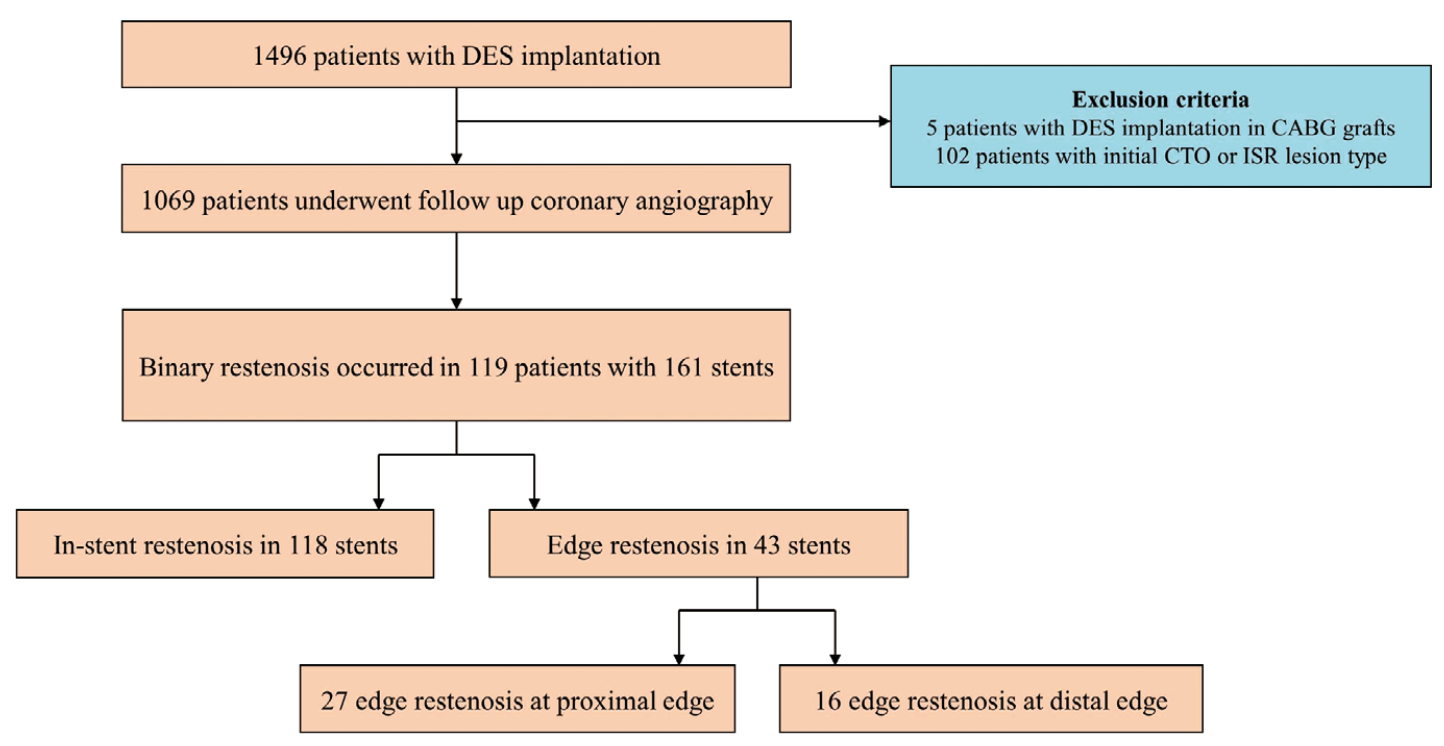

Figure 1. Flow of patients with drug-eluting stents (DES) through the study. CTO, chronic total occlusion.

Kornowski et al also demonstrated in a porcine model that inflammatory reaction plays an important role in neointimal proliferation after coronary artery stenting. ${ }^{4}$ Oversized stent or ballooning may cause acute vessel wall injury and an inflammatory reaction, which results in neointimal hyperplasia. To prevent in-stent restenosis, it might prove beneficial to minimize the degree of arterial wall injury and inflammation. Implanting stents in a tortuous artery may provoke neointimal hyperplasia because of the longitudinal straightening effect and consequent injury to the stent edge segment. Furthermore, it is plausible that stent strut thickness and flexibility related to the stent type may also affect the degree of arterial wall injury. SES have a closed-cell, stainless steel design that has low conformability and flexibility, ${ }^{15}$ thus potentially aggravating arterial wall injury at the stent edge segment.

In the present study, we hypothesized that the degree of mechanical stress determined by stent type and angulation (hinge motion) at the stent edge segment would affect the development of edge restenosis. The aim was to evaluate the relationship between mechanical stress at the stent edge segment and the development of edge restenosis.

\section{Methods}

\section{Patient Population}

Between January 2007 and January 2009, we enrolled 1,496 consecutive patients who had undergone implantation with a SES (Cypher, Cordis/Johnson and Johnson, Miami, FL, USA), PES (Taxus, Boston Scientific, Natick, MA, USA) or ZES (Endeavor, Medtronic, Fridley, MN, USA) at Seoul National University Hospital (Figure 1). We excluded 5 patients who were implanted with a DES in their coronary artery bypass grafts (CABG), and 102 patients with initial chronic total occlusion or in-stent restenosis lesion type from the study. Follow-up coronary angiography (CAG) was obtained as clinically indicated by symptoms or positive stress tests or conducted at $6-9$ months after initial percutaneous coronary intervention (PCI) for complex lesions depending on the operator's decision.
The protocols of this study were consistent with the ethical guidelines of the 1975 Helsinki Declaration, and the institutional review boards ensured appropriate ethical and bioethical conduct.

\section{CAG and Follow-up}

CAG was performed using the Judkins technique and a cineangiogram system. Intracoronary nitroglycerin was administered prior to the key angiographic image acquisitions during the stent implantation procedure and at angiographic followup. The stent diameter was selected to achieve its size closest to the media-to-media diameter. Binary restenosis was defined by diameter stenosis $>50 \%$ and classified as (1) in-stent restenosis, if inside the stent, or (2) edge restenosis, if located within the 5-mm segment proximal or distal to the stent edge margins. Target lesion revascularization was defined as repeat percutaneous or surgical procedure to the stent restenosis lesion, and stent fracture as any separation of both inner and outer struts of the angled stent.

\section{Quantification of Angulation at the Stent Edge Segment}

We evaluated maximal, minimal and $\Delta$ (maximal angle-minimal angle) angles at follow-up CAG. Both the proximal and distal edges of every stent implanted that developed restenosis were evaluated. We reviewed all standard CAG views thoroughly and images with maximal angulation at the target site were selected. For each measurement, consensus was between 2 independent observers (Won-suk Choi, MD, Moon-sun Im, MD). Angulation was measured twice at every proximal and distal edge segment (correlation coefficient 0.928, $\mathrm{P}<0.001$ ) and the mean value was used (Figure 2).

\section{Statistical Analysis}

Statistical analysis was conducted using SPSS V18.0 (SPSS Inc, Chicago, IL, USA). Values are expressed as mean \pm standard deviation. Categorical variables were compared by chi-square test or Fisher's exact test as appropriate. Continuous variables were compared by unpaired t-test. Receiver-operating charac- 


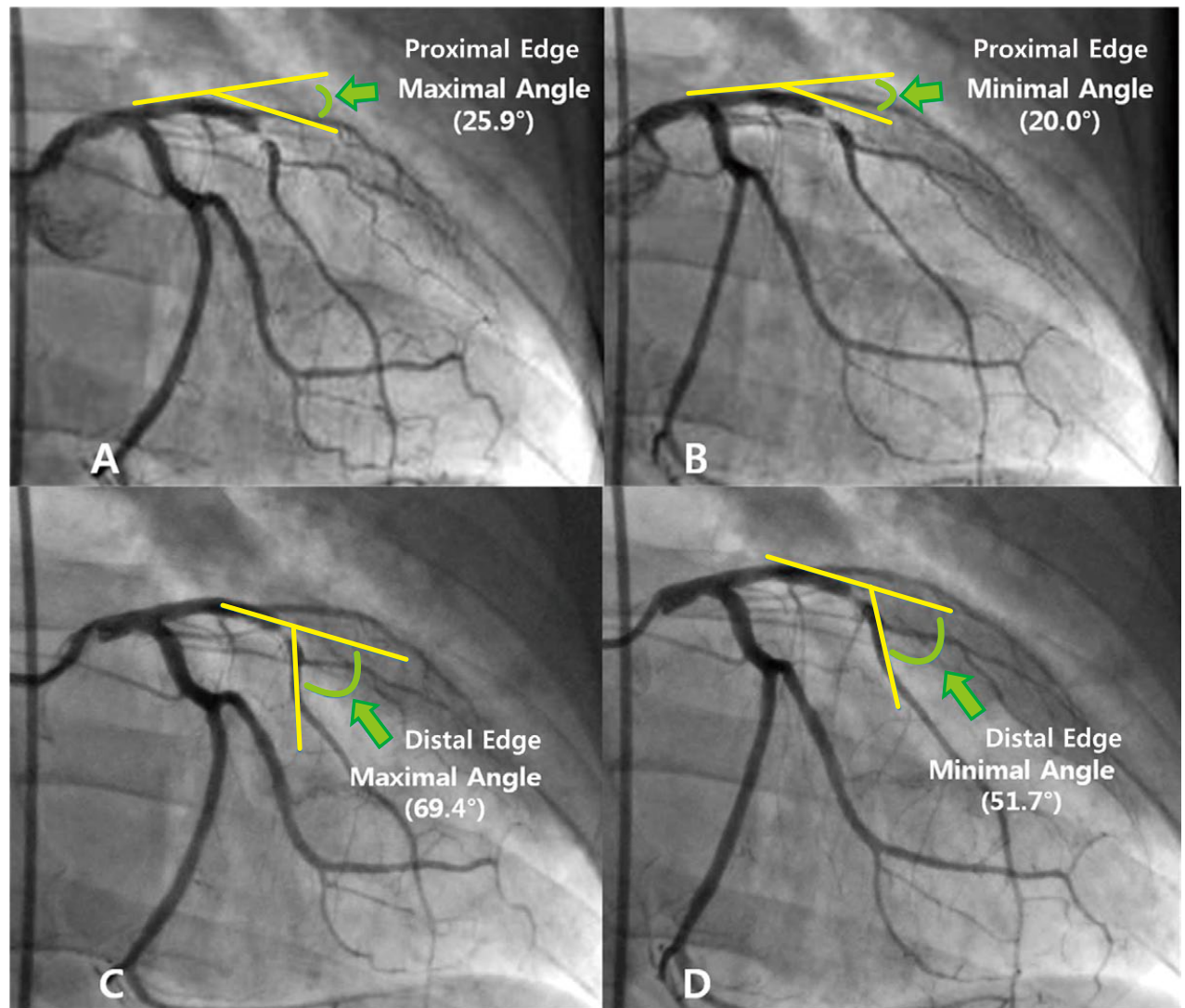

Figure 2. Representative case showing measurement of maximal, minimal, and $\Delta$ angles. In August 2007, the patient had a SES $(3.5 \times 18 \mathrm{~mm})$ implanted in the proximal left anterior descending artery. Distal edge restenosis was found in August 2009. Right anterior oblique caudal view showing distal edge restenosis: (A) maximal angle of $25.9^{\circ}$ at proximal edge, (B) minimal angle of $20.0^{\circ}$ at proximal edge, (C) maximal angle of $69.4^{\circ}$ at distal edge, (D) minimal angle of $51.7^{\circ}$ at distal edge. $\Delta$ angle at proximal and distal edges was $5.9^{\circ}$ and $17.7^{\circ}$ respectively. SES, sirolimus-eluting stent.

\begin{tabular}{|lccc|}
\hline \multicolumn{4}{|c|}{ Table 1. Baseline Clinical Characteristics of Non-Restenosis and Restenosis Groups } \\
Restenosis & $\begin{array}{c}\text { Non-restenosis } \\
(\mathbf{n}=\mathbf{1}, \mathbf{2 7 0})\end{array}$ & P value \\
Sex (M:F) & $79: 40(66.4 \%)$ & $890: 380(70.1 \%)$ & 0.402 \\
Age (years) & $64.69 \pm 8.89$ & $64.84 \pm 10.16$ & 0.884 \\
BMl (kg/m²) & $24.73 \pm 3.12$ & $24.86 \pm 3.38$ & 0.699 \\
Smoker & $24(20.2 \%)$ & $282(23.3 \%)$ & 0.435 \\
HTN & $88(79.3 \%)$ & $822(64.7 \%)$ & 0.043 \\
DM & $56(47.1 \%)$ & $437(34.4 \%)$ & 0.006 \\
CRF & $17(14.3 \%)$ & $67(5.3 \%)$ & 0.001 \\
SBP (mmHg) & $133.80 \pm 20.81$ & $129.60 \pm 23.17$ & 0.061 \\
DBP (mmHg) & $77.87 \pm 13.58$ & $77.16 \pm 12.28$ & 0.559 \\
Hb (g/dl) & $13.06 \pm 1.75$ & $13.31 \pm 1.87$ & 0.163 \\
Creatinine (mg/dl) & $1.39 \pm 1.14$ & $1.38 \pm 1.37$ & 0.974 \\
HbA1c (\%) & $6.87 \pm 1.29$ & $6.64 \pm 1.25$ & 0.094 \\
TC (mg/dl) & $164.08 \pm 36.61$ & $171.34 \pm 45.09$ & 0.089 \\
TG (mg/dl) & $148.96 \pm 76.19$ & $145.02 \pm 82.33$ & 0.627 \\
HDL (mg/dl) & $41.75 \pm 10.82$ & $43.37 \pm 11.22$ & 0.143 \\
LDL (mg/dl) & $96.71 \pm 31.82$ & $106.42 \pm 40.96$ & 0.015 \\
CRP (mg/dl) & $0.85 \pm 2.29$ & $1.28 \pm 3.90$ & 0.300 \\
\hline
\end{tabular}

BMI, body mass index; CRF, chronic renal failure; CRP, C-reactive protein; DBP, diastolic blood pressure; DM, diabetes mellitus; Hb, hemoglobin; HDL, high-density lipoprotein; HTN, hypertension; LDL, low-density lipoprotein; SBP, systolic blood pressure; TC, total cholesterol; TG, triglyceride. 


\begin{tabular}{|c|c|c|c|}
\hline & $\begin{array}{l}\text { Edge restenosis } \\
\qquad(n=25)\end{array}$ & $\begin{array}{l}\text { In-stent restenosis } \\
\qquad(n=94)\end{array}$ & $P$ value \\
\hline Sex (M:F) & $18: 7$ (72.0\%) & $61: 33(64.9 \%)$ & 0.504 \\
\hline Age (years) & $64.22 \pm 7.75$ & $64.56 \pm 8.88$ & 0.625 \\
\hline $\mathrm{BMI}\left(\mathrm{kg} / \mathrm{m}^{2}\right)$ & $25.24 \pm 2.66$ & $24.60 \pm 3.24$ & 0.366 \\
\hline Smoker & $6(22.2 \%)$ & $21(19.6 \%)$ & 0.764 \\
\hline HTN & $18(72.0 \%)$ & $70(74.5 \%)$ & 0.803 \\
\hline DM & $8(32.0 \%)$ & $48(51.0 \%)$ & 0.090 \\
\hline CRF & $2(11.8 \%)$ & $15(16.0 \%)$ & 0.520 \\
\hline $\mathrm{SBP}(\mathrm{mmHg})$ & $127.92 \pm 17.69$ & $135.36 \pm 21.38$ & 0.112 \\
\hline $\mathrm{DBP}(\mathrm{mmHg})$ & $77.16 \pm 12.24$ & $78.05 \pm 13.97$ & 0.771 \\
\hline $\mathrm{Hb}(\mathrm{g} / \mathrm{dl})$ & $13.36 \pm 1.34$ & $12.98 \pm 1.84$ & 0.247 \\
\hline Creatinine (mg/dl) & $1.14 \pm 0.27$ & $1.45 \pm 1.27$ & 0.235 \\
\hline HbA1c (\%) & $6.75 \pm 1.15$ & $6.89 \pm 1.33$ & 0.693 \\
\hline TC (mg/dl) & $155.72 \pm 32.90$ & $166.30 \pm 37.38$ & 0.200 \\
\hline TG (mg/dl) & $115.17 \pm 42.14$ & $158.07 \pm 80.80$ & 0.014 \\
\hline $\mathrm{HDL}(\mathrm{mg} / \mathrm{dl})$ & $44.21 \pm 14.37$ & $41.09 \pm 9.64$ & 0.212 \\
\hline LDL (mg/dl) & $89.78 \pm 31.72$ & $98.49 \pm 31.77$ & 0.243 \\
\hline CRP (mg/dl) & $0.68 \pm 0.86$ & $0.91 \pm 2.58$ & 0.679 \\
\hline Diagnosis & & & 0.343 \\
\hline Stable angina & $21(84.0 \%)$ & $60(63.8 \%)$ & \\
\hline Unstable angina & $3(12.0 \%)$ & $18(19.1 \%)$ & \\
\hline NSTEMI & $0(0.0 \%)$ & $6(6.4 \%)$ & \\
\hline STEMI & $1(4.0 \%)$ & $7(7.4 \%)$ & \\
\hline OMI & $0(0 \%)$ & $3(3.2 \%)$ & \\
\hline \multicolumn{4}{|l|}{ Medications } \\
\hline Aspirin & $25(100 \%)$ & 95 (100\%) & \\
\hline ADP receptor inhibitor & $25(100 \%)$ & 95 (100\%) & \\
\hline$\beta$-blocker & $17(68 \%)$ & $62(66 \%)$ & 0.848 \\
\hline ACEI, ARB & $10(40.0 \%)$ & $52(55.3 \%)$ & 0.091 \\
\hline Statins & 22 (88\%) & 85 (90.4\%) & 0.714 \\
\hline
\end{tabular}

ACEI, angiotensin-converting enzyme inhibitor; ADP, adenosine diphosphate; ARB, angiotensin receptor blocker; NSTEMI, non-ST-elevation myocardial infarction; OMI, old myocardial infarction; STEMI, ST-elevation myocardial infarction. Other abbreviations as in Table 1.

teristic (ROC) curves were used to assess the diagnostic value of angulation at the edge segment in predicting the development of edge restenosis. All tests of significance were 2-tailed and $\mathrm{P}<0.05$ was considered to indicate statistical significance.

\section{Results}

\section{Clinical and Angiographic Characteristics}

Of the 1,389 patients, 1,069 (77.0\%) underwent follow-up CAG and $320(23.0 \%)$ did not (baseline clinical and angiographic characteristics are summarized in Table S1). Of the 1,069 patients who underwent follow-up CAG, binary restenosis occurred in 119 patients and 161 target lesions. Of the 161 lesions with restenosis, in-stent restenosis occurred in 118 lesions and edge restenosis occurred in 43 lesions. Of the 43 cases of edge restenosis, 27 involved the proximal edge and 16 the distal edge. Overall study flow is summarized in Figure 1.

SES were implanted in 557 patients with a total of 753 stents and $58.5 \%$ of the patients (326/557 patients) had followup CAG. PES were implanted in 512 patients with 834 stents, and $78.7 \%$ of patients (403/512 patients) had follow-up CAG. ZES were implanted in 404 patients with total 633 stents and $75.0 \%$ of patients (303/404 patients) had follow-up CAG.

Baseline clinical and angiographic characteristics of the re- stenosis and non-restenosis groups are shown in Table 1. Diabetes mellitus and chronic renal failure (CRF) were significantly more prevalent in the restenosis group than in the non-restenosis group, which was in accordance with previous reports. ${ }^{15,16}$ Hypertension was also more prevalent in the restenosis group. Baseline clinical and angiographic characteristics of the edge restenosis and the in-stent restenosis groups are shown in Table 2 and Table 3 . The 2 groups did not differ significantly in terms of most of the clinical variables. However, calcification at the target lesion site was more common in the edge restenosis group than in the in-stent restenosis group.

Comparison of Edge Restenosis Rate According to DES Type After implanting 753 SES in 557 patients, a total of 34 stents developed restenosis, 20 developed in-stent restenosis and 14 developed edge restenosis ( 8 at the proximal edge, 6 at the distal edge). Among 834 PES implantations, a total of 63 stents developed restenosis, comprising 46 cases of in-stent restenosis and 17 of edge restenosis ( 13 at the proximal edge, 4 at the distal edge). Among the 633 ZES, a total of 64 stents developed restenosis, 52 in-stent restenosis and 12 edge restenosis ( 6 cases each for the proximal and distal edges). The percentage of edge restenosis among total stent restenosis was higher for SES than for ZES (41.2\% vs. 18.8\%, $\mathrm{P}=0.017)$. There were 


\begin{tabular}{|c|c|c|c|}
\hline & $\begin{array}{l}\text { Edge restenosis } \\
\qquad(n=43)\end{array}$ & $\begin{array}{l}\text { In-stent restenosis } \\
\quad(n=118)\end{array}$ & $P$ value \\
\hline Target vessel (n, \%) & & & 0.714 \\
\hline LMCA & $3(7.0 \%)$ & $3(2.5 \%)$ & \\
\hline LAD & $20(46.5 \%)$ & $58(49.2 \%)$ & \\
\hline RI & $0(0.0 \%)$ & $1(0.8 \%)$ & \\
\hline LCX & $8(18.6 \%)$ & $21(17.8 \%)$ & \\
\hline RCA & $12(27.9 \%)$ & $35(29.7 \%)$ & \\
\hline Stent length & $27.67 \pm 6.92$ & $26.64 \pm 7.47$ & 0.435 \\
\hline Stent diameter & $3.04 \pm 3.67$ & $2.92 \pm 0.33$ & 0.052 \\
\hline Diffuse lesion $(\geq 2 \mathrm{~cm})$ & $20(46.5 \%)$ & $69(58.5 \%)$ & 0.177 \\
\hline Thrombosis & $0(0.0 \%)$ & $3(2.5 \%)$ & 0.565 \\
\hline Calcification & $7(16.3 \%)$ & $4(3.4 \%)$ & 0.009 \\
\hline Bifurcation stenting & $19(44.2 \%)$ & $52(44.1 \%)$ & 0.989 \\
\hline Ostial & $7(16.3 \%)$ & $9(7.6 \%)$ & 0.135 \\
\hline Stent underexpansion & $1(2.3 \%)$ & $3(2.5 \%)$ & 1.000 \\
\hline Residual stenosis & $1(2.3 \%)$ & $3(2.5 \%)$ & 1.000 \\
\hline Side branch occlusion & $1(2.3 \%)$ & $6(5.1 \%)$ & 0.676 \\
\hline Coronary artery perforation & $3(7.0 \%)$ & $2(1.7 \%)$ & 0.119 \\
\hline Dissection & $2(4.7 \%)$ & $6(5.1 \%)$ & 1.000 \\
\hline No-reflow phenomenon & $0(0.0 \%)$ & $0(0.0 \%)$ & \\
\hline Stent fracture & $0(0.0 \%)$ & $0(0.0 \%)$ & \\
\hline Emergency procedure & $1(2.3 \%)$ & $6(5.1 \%)$ & 0.676 \\
\hline IVUS & $26(60.5 \%)$ & $60(50.8 \%)$ & 0.279 \\
\hline Rotablator & $0(0.0 \%)$ & $0(0.0 \%)$ & \\
\hline Stent length to lesion length ratio & $2.15 \pm 1.30$ & $2.24 \pm 1.45$ & 0.803 \\
\hline
\end{tabular}

Residual stenosis: residual stenosis of more than $20 \%$ according to operator's judgment based on IVUS or angiographic images.

Stent fracture: any separation of both inner and outer struts of the angled stent, which was assessed by cine angiogram.

Stent underexpansion: lack of contact between any strut and the underlying vessel wall on IVUS images or according to operator's judgment based on angiographic images.

IVUS, intravascular ultrasonography; LAD, left anterior descending; LCX, left circumflex; LMCA, left main coronary artery; RCA, right coronary artery; RI, ramus intermedius.

\begin{tabular}{|lccc|}
\hline \multicolumn{4}{|c|}{ Table 4. Comparison of the Edge Restenosis Rate According to DES Type } \\
\\
Restenosis stent/whole stent & SES & PES & ZES \\
In-stent restenosis lesion & $34 / 753(4.5 \%)$ & $63 / 834(7.6 \%)$ & $64 / 633(10.1 \%)$ \\
Edge restenosis lesion & 20 & 46 & 52 \\
Proximal edge restenosis & 14 & 17 & 12 \\
Distal edge restenosis & 8 & 13 & 6 \\
Edge restenosis (\%) & 6 & 4 & 6 \\
\hline
\end{tabular}

Edge restenosis (\%): (edge restenosis/all restenosis) $\times 100$.

${ }^{a}$ Comparing edge restenosis rate of SES vs. ZES, $P=0.017$. ${ }^{b}$ Comparing edge restenosis rate of SES vs. PES,

$P=0.153$. ${ }^{\circ}$ Comparing edge restenosis rate of $P E S$ vs. $Z E S, P=0.269$.

PES, paclitaxel-eluting stent; SES, sirolimus-eluting stent; ZES zotarolimus-eluting stent.

no statistically significant differences in the edge restenosis rate between SES and PES or between PES and ZES (Table 4).

\section{Angulation at Target Stented Lesion}

Among 161 stents with restenosis, 115 were eligible for evaluation of the angulation at the proximal edge. Of the remainder, in 36 stents the proximal edge angulation could not be evaluated because the stent proximal edge overlapped another proximal stent, there were no stored images for 5 stents and poor quality images for 5 stents.
The maximal angulation at the proximal edge was $64.82^{\circ} \pm$ $33.46^{\circ}$ for 26 stents with proximal edge restenosis compared with $31.84^{\circ} \pm 31.51^{\circ}$ for 89 stents without proximal edge restenosis $(\mathrm{P}=0.001)$. The $\Delta$ angle also showed a significant difference between the 2 groups $\left(14.81^{\circ} \pm 15.98^{\circ}\right.$ vs. $7.60^{\circ} \pm 8.86^{\circ}$, $\mathrm{P}=0.035$ ).

We also analyzed the angulation at the distal edge in 122 stents among the total of 161 stents with restenosis. In 30 stents we could not measure the distal edge angulation because of another overlapping stent implanted at stent distal edge, 

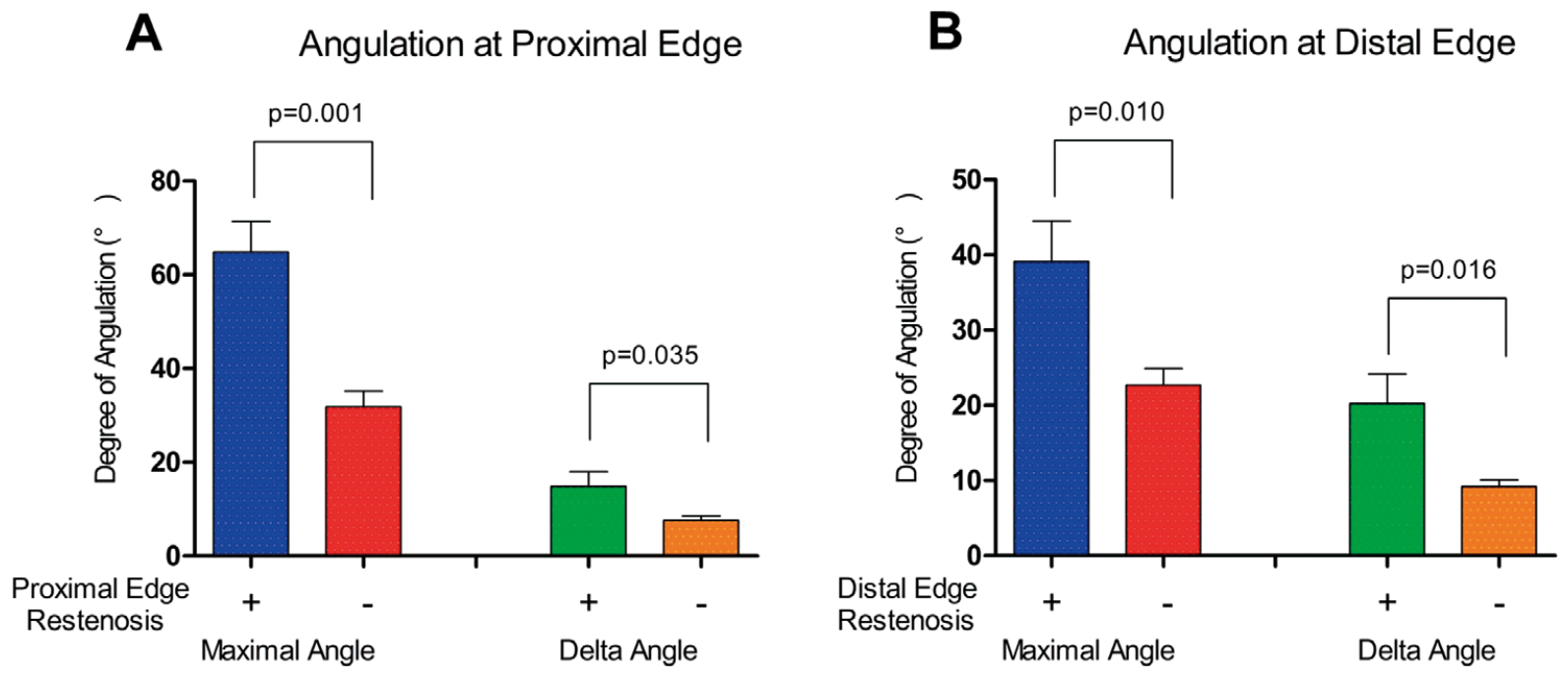

Figure 3. (A) Angulation at the stent proximal edge. Stents with proximal edge restenosis showed significantly higher degrees of the maximal and $\Delta$ angles. (B) Angulation at the stent distal edge. Higher degrees of maximal and $\Delta$ angles were observed for stents with distal edge restenosis.
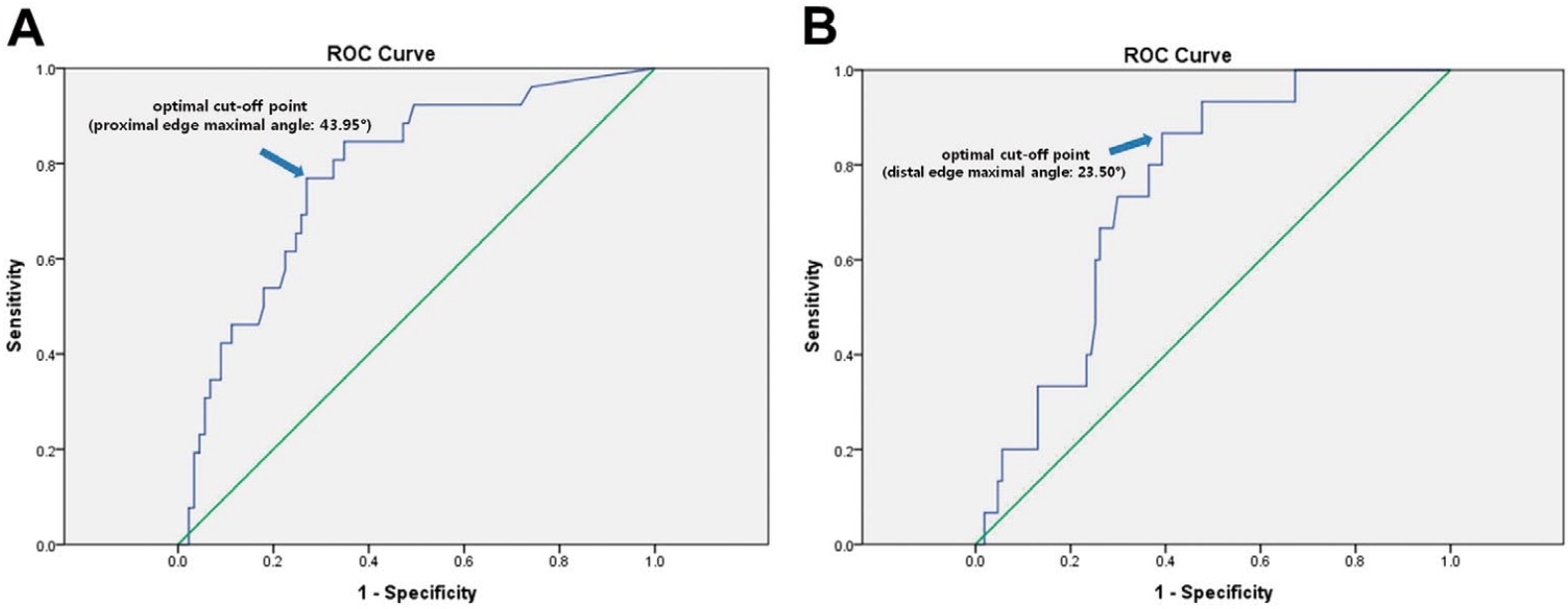

Figure 4. Receiver-operating characteristic $(\mathrm{ROC})$ curve analysis of the maximal angle at the proximal and distal edges in predicting the development of edge restenosis. (A) Optimal cut off point of maximal angle at proximal edge segment was $43.95^{\circ}$ (area under curve $0.779,95 \%$ confidence interval $0.681-0.877, \mathrm{P}<0.001)$. (B) Optimal cut off point of maximal angle at distal edge segment was $23.50^{\circ}$ (area under curve $0.745,95 \%$ confidence interval $0.640-0.849, \mathrm{P}=0.002$ ).

there were no stored images for 5 stents and poor quality images for 4 stents. The maximal angulation at the distal edge was $39.09^{\circ} \pm 21.04^{\circ}$ in 15 stents with distal edge restenosis compared with $22.71^{\circ} \pm 22.83^{\circ}$ in 107 stents without distal edge restenosis $(\mathrm{P}=0.010)$. The $\Delta$ angle was also significantly different between the 2 groups $\left(20.23^{\circ} \pm 15.39^{\circ}\right.$ vs. $9.18^{\circ} \pm 9.66^{\circ}$, $\mathrm{P}=0.016)$. Results are summarized in Figure 3.

Figure 4 shows the ROC curve analysis of the maximal angle at the proximal/distal edge for predicting the development of edge restenosis at each site. The area under the curve was 0.779 for the proximal edge maximal angle and 0.745 for the distal edge maximal angle. See also Table S6 and S7 for multivariate analysis using logistic regression model to predict the development of edge restenosis.

\section{Discussion}

This study reports on the relationship between mechanical stress imposed on the stent edge segment and the development of edge restenosis after DES implantation. By careful retrospective angiographic analysis of all lesions that developed restenosis (both in-stent and at the edge segment) after DES 
implantation, we raise the hypothesis that severe angulation at the stent edge segment and a high degree of stiffness of the stent, such as with SES, are associated with the development of edge restenosis.

The pattern of restenosis lesions after SES implantation is usually focal and mostly inside the stent. ${ }^{17,18}$ However, edge restenosis still occurs after DES implantation. Kitahara et al reported 98 cases of focal $(79.0 \%)$ and 26 of non-focal restenosis $(21.0 \%)$ among 124 in-stent restenosis lesions after SES implantation, and proximal edge restenosis occurred in 22 lesions $(17.7 \%) .{ }^{12}$ When we analyzed the factors associated with edge restenosis after DES implantation, it was significantly related to the angulation at the target lesion site. DES type also seemed to influence the development of edge restenosis, which is thought to be the effect of differences in stent strut thickness and flexibility. One mechanism of stent-induced damage is metallic struts that injure the vascular wall, which corresponds to the extent of intimal thickening in experimental animals. ${ }^{14,19-21}$ Briguori et al demonstrated that stent strut thickness is an independent predictor of restenosis in coronary arteries. ${ }^{22}$ The concept that stent strut thickness affects restenosis could further extend to edge restenosis according to our study results.

When a DES is implanted into a tortuous coronary artery, the stented segment is straightened, but that with the edge of the stent is more angulated, which leads to the formation of a hinge point between the stented and unstented segments of the vessel with every heart contraction. Mechanical injury at the edge segment because of the hinge motion might contribute to chronic local inflammation and neointimal overgrowth. In our study, calcification at the edge segment was observed more frequently in the edge restenosis group than in the in-stent restenosis group, which supports the hypothesis that mechanical stress imposed at the edge segment affects the development of edge restenosis.

However, edge restenosis cannot be explained by a single theory and there are several other hypotheses of the mechanism. A unique characteristic of patients with edge restenosis is that they have restenosis lesions relatively localized at the stent margin, with most of the remaining stent length free from significant restenosis lesions. ${ }^{23}$ Another major characteristic of this subgroup is that in most patients the lesion also affects the adjacent unscaffolded vessel for a variable length. ${ }^{24}$ Therefore, these patients share characteristics of in-stent restenosis lesions and of classic restenosis lesions after balloon angioplasty. ${ }^{23}$ It is plausible to think that edge restenosis is the result of a combination of neointimal hyperplasia and negative remodeling. Hoffmann et al showed that edge restenosis after bare-metal stent implantation was a combination of neointimal hyperplasia closest to the stent edge and progressively more negative remodeling at distances remote from the stent edge. ${ }^{25}$ Others have demonstrated that the plaque burden at the SES edge was associated with negative remodeling at follow-up, ${ }^{26}$ and Ahmed et al demonstrated that edge restenosis after brachytherapy was the result of neointimal hyperplasia and the absence of radiation-induced positive remodeling. ${ }^{27}$ Thus, negative remodeling, increased plaque size because of disease progression, and neointimal hyperplasia may all have a role in the development of edge restenosis. Although our study focused mainly on the hypothesis that mechanical stress can lead to neointimal hyperplasia, we need a comprehensive understanding of the diverse factors leading to edge restenosis after PCI.

\section{Study Limitations}

First, this was an observational, retrospective, and single-cen- ter-based study. The total number of patients who had restenosis was not large (119 patients, 161 lesions), so larger clinical trials are required to confirm the data from our study. Second, follow-up CAG was not performed in $23.0 \%$ of all patients. Furthermore, the follow-up angiography rate was especially low in the SES group. There were also some differences between patients with and without follow-up angiography, such as baseline level of creatinine, the rate of patients with CRF, and the rate of performing intravascular ultrasonography. We cannot exclude the possibility that there might have been a selection bias. Third, the angulation at the edge segment was measured with a standard angiographic view instead of a 3 -dimensional imaging technique. To overcome this potential limitation, we thoroughly reviewed all views of standard coronary angiograms and selected the maximal angulation at the target lesion site. Measurement of angulation required consensus from 2 independent observers. Fourth, not only mechanical properties of the stent but also different drug action mechanisms and delivery platforms may translate into different edge vascular responses as well as intrastent responses. How the different drug mechanism and delivery platforms affect the development of edge restenosis needs further investigation.

\section{Conclusions}

With technical advances, DES are being implanted in increasing numbers of complex and tortuous lesions. We suggest the hypothesis that DES type and angulation at the stent edge segment may influence the development of stent edge restenosis. When implanting a DES in a tortuous lesions, it would be important to decide the stent-landing zone for the angle of the edge to be minimal and to choose a newer generation DES that has an open cell design and better flexibility.

\section{Acknowledgments}

This study was supported by grants from the Innovative Research Institute for Cell Therapy, Seoul National University Hospital (A062260) and Korean Health Technology R\&D Project (A100476) sponsored by the Ministry of Health, Welfare \& Family, Republic of Korea.

\section{Disclosures}

Competing interests: The authors declare that they have no competing interests. Authors' contributions: The original manuscript was written by Yun Gi Kim. All authors contributed to drafting and editing the manuscript. All authors read and approved the final manuscript.

\section{References}

1. Kent KM. Restenosis after percutaneous transluminal coronary angioplasty. Am J Cardiol 1988; 61: 67G-70G.

2. Nobuyoshi M, Kimura T, Nosaka H, Mioka S, Ueno K, Yokoi H, et al. Restenosis after successful percutaneous transluminal coronary angioplasty: Serial angiographic follow-up of 229 patients. J Am Coll Cardiol 1988; 12: 616-623.

3. McBride W, Lange RA, Hillis LD. Restenosis after successful coronary angioplasty: Pathophysiology and prevention. $N$ Engl J Med 1988; 318: 1734-1737.

4. Kornowski R, Hong MK, Tio FO, Bramwell O, Wu H, Leon MB. In-stent restenosis: Contributions of inflammatory responses and arterial injury to neointimal hyperplasia. J Am Coll Cardiol 1998; 31: 224-230.

5. Park KW, Hwang SJ, Kwon DA, Oh BH, Park YB, Chae IH, et al. Characteristics and predictors of drug-eluting stent thrombosis: Results from the multicenter 'Korea Stent Thrombosis (KoST)' registry. Circ J 2011; 75: 1626-1632.

6. Hwang SJ, Park KW, Kwon DA, Kang HJ, Koo BK, Chae IH, et al. High plasma interleukin-6 is associated with drug-eluting stent thrombosis: Possible role of inflammatory cytokines in the development of stent thrombosis from the Korea Stent Thrombosis Registry. Circ J 2011; 75: 1350-1357. 
7. Morice MC, Serruys PW, Sousa JE, Fajadet J, Ban Hayashi E, Perin $\mathrm{M}$, et al. A randomized comparison of a sirolimus-eluting stent with a standard stent for coronary revascularization. $N$ Engl J Med 2002; 346: $1773-1780$.

8. Teirstein PS, Massullo V, Jani S, Popma JJ, Mintz GS, Russo RJ, et al. Catheter-based radiotherapy to inhibit restenosis after coronary stenting. N Engl J Med 1997; 336: 1697-1703.

9. Kuchulakanti PK, Chu WW, Torguson R, Ohlmann P, Rha SW, Clavijo LC, et al. Correlates and long-term outcomes of angiographically proven stent thrombosis with sirolimus- and paclitaxel-eluting stents. Circulation 2006; 113: 1108-1113.

10. Ahmed K, Jeong MH, Chakraborty R, Ahmed S, Hong YJ, Sim DS, et al. Coronary stents in patients with ST-elevation myocardial infarction and chronic kidney disease undergoing primary percutaneous coronary intervention. Korean Circ J 2012; 42: 830-838.

11. Lee SP, Bae JW, Park KW, Rha SW, Bae JH, Suh JW, et al. Inhibitory interaction between calcium channel blocker and clopidogrel Efficacy of cilostazol to overcome it. Circ J 2011; 75: 2581-2589.

12. Kitahara H, Kobayashi Y, Takebayashi H, Nakamura Y, Kuroda N, Miyazaki A, et al. Angiographic patterns of restenosis after sirolimuseluting stent implantation. Circ J 2009; 73: 508-511.

13. Lemos PA, Saia F, Ligthart JM, Arampatzis CA, Sianos G, Tanabe K, et al. Coronary restenosis after sirolimus-eluting stent implantation: Morphological description and mechanistic analysis from a consecutive series of cases. Circulation 2003; 108: 257-260.

14. Schwartz RS, Huber KC, Murphy JG, Edwards WD, Camrud AR, Vlietstra RE, et al. Restenosis and the proportional neointimal response to coronary artery injury: Results in a porcine model. $J$ Am Coll Cardiol 1992; 19: 267-274.

15. Ino Y, Kubo T, Kitabata H, Shimamura K, Shiono Y, Orii M, et al. Impact of hinge motion on in-stent restenosis after sirolimus-eluting stent implantation. Circ J 2011; 75: 1878-1884.

16. Takeuchi I, Moriguchi M, Imaki R, Fukaya $H$, Shinagawa $H$, Shimohama T, et al. Hemodialysis is an independent predictor of coronary in-stent restenosis after paclitaxel eluting stent implantation. Intern Med 2010; 49: 2379-2384.

17. Park KW, Kim HS. Options to overcome clopidogrel response variability. Circ J 2012; 76: 287-292.

18. Colombo A, Orlic D, Stankovic G, Corvaja N, Spanos V, Montorfano $\mathrm{M}$, et al. Preliminary observations regarding angiographic pattern of restenosis after rapamycin-eluting stent implantation. Circulation 2003; 107: $2178-2180$

19. Lurz P, Nordmeyer J, Muthurangu V, Khambadkone S, Derrick G, Yates R, et al. Comparison of bare metal stenting and percutaneous pulmonary valve implantation for treatment of right ventricular outflow tract obstruction: Use of an $\mathrm{x}$-ray/magnetic resonance hybrid laboratory for acute physiological assessment. Circulation 2009; 119: 2995-3001.

20. Garasic JM, Edelman ER, Squire JC, Seifert P, Williams MS, Rogers $C$. Stent and artery geometry determine intimal thickening independent of arterial injury. Circulation 2000; 101: 812-818.

21. Rogers C, Parikh S, Seifert P, Edelman ER. Endogenous cell seed- ing: Remnant endothelium after stenting enhances vascular repair. Circulation 1996; 94: 2909-2914.

22. Briguori C, Sarais C, Pagnotta P, Liistro F, Montorfano M, Chieffo $\mathrm{A}$, et al. In-stent restenosis in small coronary arteries: Impact of strut thickness. J Am Coll Cardiol 2002; 40: 403-409.

23. Alfonso F, Melgares R, Mainar V, Lezaun R, Vazquez N, Tascon J, et al. Therapeutic implications of in-stent restenosis located at the stent edge: Insights from the restenosis intra-stent balloon angioplasty versus elective stenting (RIBS) randomized trial. Eur Heart J 2004; 25: $1829-1835$

24. Mehran R, Dangas G, Abizaid AS, Mintz GS, Lansky AJ, Satler LF, et al. Angiographic patterns of in-stent restenosis: Classification and implications for long-term outcome. Circulation 1999; 100: $1872-$ 1878.

25. Hoffmann R, Mintz GS, Kent KM, Satler LF, Pichard AD, Popma $\mathrm{JJ}$, et al. Serial intravascular ultrasound predictors of restenosis at the margins of Palmaz-Schatz stents. Am J Cardiol 1997; 79: 951 -953.

26. Sakurai R, Ako J, Morino Y, Sonoda S, Kaneda H, Terashima M, et al. Predictors of edge stenosis following sirolimus-eluting stent deployment (a quantitative intravascular ultrasound analysis from the SIRIUS trial). Am J Cardiol 2005; 96: 1251-1253.

27. Ahmed JM, Mintz GS, Waksman R, Lansky AJ, Mehran R, Wu H, et al. Serial intravascular ultrasound analysis of edge recurrence after intracoronary gamma radiation treatment of native artery in-stent restenosis lesions. Am J Cardiol 2001; 87: 1145-1149.

\section{Supplementary Files}

Supplementary File 1

Table S1. Baseline clinical and angiographic characteristics of the patients with and without follow-up angiography

Table S2. Hinge motion rate at proximal edge segment in patients with proximal edge restenosis

Table S3. Hinge motion rate at distal edge segment in patients with distal edge restenosis

Table S4. Rate of calcification at proximal edge segment

Table S5. Rate of calcification at distal edge segment

Table S6. Multivariate logistic regression analysis of independent predictors of proximal edge restenosis

Table S7. Multivariate logistic regression analysis of independent predictors of distal edge restenosis

Table S8. Angulation data at initial percutaneous coronary intervention

Table S9. Angulation data at follow-up angiography

Please find supplementary file(s);

http://dx.doi.org/10.1253/circj.CJ-12-1259 